\title{
LA EXPLOTACIÓN DE RECURSOS FAUNÍSTICOS EN EL SITIO PUNTA SANTA ANA 1: ESTRATEGIAS DE SUBSISTENCIA DE GRUPOS DE CAZADORES MARINOS TEMPRANOS DE PATAGONIA MERIDIONAL. ${ }^{1}$
}

MANUEL SAN ROMÁN

\section{RESUMEN}

A partir del análisis arqueozoológico del sitio Punta Santa Ana 1 y la integración de resultados previamente publicados para otros yacimientos de cazadores marinos tempranos de Patagonia, se describen y discuten modalidades de explotación de recursos animales y estrategias de subsistencia desarrolladas por grupos adscritos a la tradición cultural Englefield, desarrollada en Patagonia meridional entre el V y III milenio antes de nuestra era.

La aplicación de índices de utilidad económica, de densidad mineral ósea y la incorporación de otras fuentes de información, permiten discutir algunas propiedades para el conjunto de yacimientos de tradición Englefield que cuentan con información arqueozoológica detallada. Los resultados permiten plantear al menos dos tipos de yacimientos residenciales, a partir de la intensidad de uso y modalidades de consumo de pinnípedos. Esta diferenciación de conjuntos puede tener como explicación las estrategias de movilidad y el uso diferenciado del espacio por parte de estos grupos de cazadores recolectores marinos tempranos.

PALABRAS CLAVES: Cazadores marinos tempranos, Patagonia meridional, consumo y descarte diferencial de presas, movilidad.

\section{FAUNA RESOURCE EXPLOITATION IN PUNTA SANTA ANA 1 SITE: SUBSISTENCE STRATEGIES OF EARLY MARINE HUNTERS OF SOUTHERN PATAGONIA.}

\section{ABSTRACT}

From the archaeozoological analysis of Punta Santa Ana 1 site and its integration with previously published results from other early marine hunter records of Patagonia, animal resource modalities and subsistence strategies are described and discussed for groups assigned to the Englefield cultural tradition that developed in Southern Patagonia between the V and III millennium before Christ.

Proyecto FONDECYT 1085329.

Investigador asociado del Centro de Estudios del Hombre Austral, Instituto de la Patagonia, Universidad de Magallanes. Avenida Bulnes 01890, casilla 113-D, Punta Arenas. Email: msanromanbontes@gmail.com 
The application of economic utility indices, bone mineral density and the incorporation of other information sources, allowed discussing some characteristics of the assemblage of Englefield tradition sites that count with detailed archaeozoological information. The results allow us to propose at least two types of residential sites, from the intensity of use and pinniped consumption modalities. These set differentiations can have an explanation in mobility strategies and differentiated space use by the part of early marine hunter-gatherer groups.

KEYWORDS: early marine hunters, southern Patagonia, consumption, differential prey discard, mobility.

\section{INTRODUCCIÓN}

Las evidencias de los primeros grupos de cazadores-recolectores marítimos de Patagonia han sido registradas en antiguos bordes costeros, emplazados en cotas iguales o mayores a 10 metros snm actual. Una de las localidades que concentra yacimientos de éste período corresponde a la isla Englefield, emplazada en medio del mar de Otway. En ésta se identificaron los sitios Englefield 1 (Emperaire y Laming 1961), Bahía Colorada (Legoupil 1997), Pizzulic 1 y Pizzulic 2 (San Román 2005; San Román, et al. 2002). La otra zona que concentra evidencias corresponde al borde sureste de península Brunswick, específicamente el sistema de pequeñas bahías asociadas a la Punta Santa Ana, en el estrecho de Magallanes. Allí se ubican Bahía Buena (Ortiz-Troncoso 1975), Punta Santa Ana 1 (op. cit.) y Punta Carrera (Ocampo, 1994) [Fig. 1].

Las fechas radiocarbónicas obtenidas para estos yacimientos los ubican en un rango cronológico comprendido entre 6500 a 5000 años AP (no calibrados), destacando el alto grado de estandarización de la industria lítica y ósea, hecho que condujo a la adscripción de éstos dentro de una tradición cultural denominada Englefield (Ortiz-Troncoso 1975, Legoupil 1997). En particular, destaca la industria ósea caracterizada por

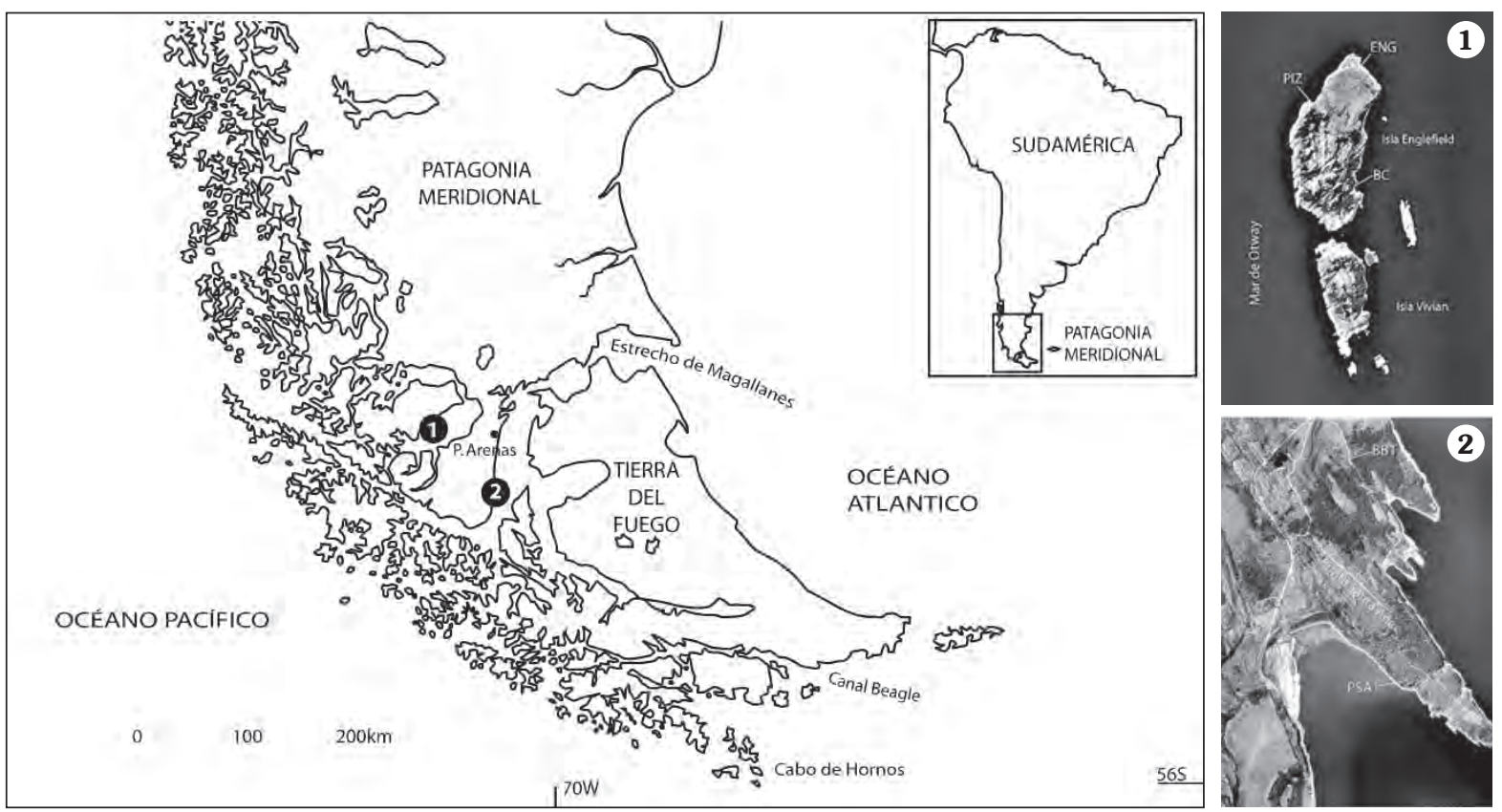

Fig. 1. Ubicación de sitios de cazadores marítimos tempranos de Patagonia Meridional. ENG: Englefield, PIZ: Pizzulic 1 y 2 , BC: Bahía Colorada, BB1: Bahía Buena 1, y PSA1: Punta Santa Ana 1. 
arpones de base cruciforme y cinceles confeccionados sobre ulnas de otáridos. Además, se agregan algunos elementos de adorno como pendientes, generalmente sobre caninos de pinnípedo, la decoración de artefactos tales como arpones, retocadores y espátulas con motivos geométricos grabados (Emperaire y Laming 1961; Ortiz-Troncoso 1975; Legoupil 1997; San Román 2005). Para la industria lítica, destaca la profusa utilización de obsidiana verde, siendo muy importante la industria bifacial (Schidlowsky 1999). Otros elementos recurrentes entre los conjuntos líticos son los guijarros con surcos y/o escotaduras, presumiblemente utilizados como pesas de línea o red para la pesca. Resulta interesante señalar que no se han registrado anzuelos en ninguno de los sitios tempranos. También se registran rocas piqueteadas y pulidas de formas alargadas, morfológicamente parecidas a hachas (Legoupil 1997:139; San Román et al. 2009).

En relación a la economía de subsistencia, la información arqueozoológica publicada para los yacimientos de Bahía Colorada y Bahía Buena ha permitido establecer que los otáridos, específicamente Arctocephalus australis [Zimmermann 1783], habrían constituido el principal aporte energético en la dieta de estas poblaciones de cazadores. (Legoupil 1997; San Román 2004, 2007), complementada por diversas especies de aves de ámbito marino, siendo predominantes los cormoranes (Lefèvre 1989). Otros animales como delfines, camélidos y cérvidos, aparecen representados con una baja frecuencia. Si bien, las tendencias aquí esbozadas configuran un marco básico para la caracterización de esta tradición cultural, nos parece relevante discutir otras dimensiones asociadas a la subsistencia que permitan ampliar nuestra comprensión sobre aspectos sistémicos de estos grupos de cazadores.

A partir del análisis arqueozoológico del sitio Punta Santa Ana 1 y la integración de resultados previamente publicados para otros yacimientos de cazadores marinos adscritos a la tradición Englefield, se describirán y discutirán aspectos referidos a las estrategias de explotación de recursos faunísticos, específicamente de mamíferos, intentando demostrar que a partir de evidencias de consumo diferencial de carcasas de pinnípedos y otras evidencias, se puede inferir la existencia de una diferenciación entre tipo de sitios residenciales para grupos portadores de esta tradición cultural, probablemente asociadas a las estrategias de movilidad desplegadas por éstos en los bordes costeros del archipiélago patagónico meridional.

\section{ANTECEDENTES}

La información disponible sobre explotación de recursos animales para grupos asignados a la tradición Englefield, específicamente la referida a mamíferos, corresponde a los yacimientos de Bahía Colorada y Bahía Buena, ubicados en isla Englefield y en el estrecho de Magallanes, respectivamente. A continuación sintetizamos los principales aspectos de cada uno de estos yacimientos, agregando al final de la sección los principales antecedentes referidos al yacimiento de Punta Santa Ana 1, sobre el que efectuamos un análisis arqueozoológico.

El yacimiento de Bahía Colorada $(\mathrm{BC})$ fue excavado íntegramente $\left(97 \mathrm{~m}^{2}\right)$ por la expedición arqueológica francesa liderada por Dominique Legoupil, en la década de 1980. El sitio corresponde a un campamento residencial con evidencias de una estructura de vivienda (choza), áreas de actividad y basurales periféricos a ésta. La única fecha radiocarbónica le asigna una antigüedad de 5000£70 años AP (Legoupil 1997).

En relación a la información paleo-económica disponible para el sitio, presentamos una síntesis en la Tabla 1.

Basados en los análisis efectuados por Legoupil (op cit.), podemos señalar que una característica notable para este yacimiento corresponde a la abrumadora predominancia de restos de otárido, habiéndose identificado Arctocephalus australis como especie dominante para el conjunto. En relación a la estructura de edades de los pinnípedos recuperados, se observa la alta frecuencia de adultos, con 51 individuos, seguidos por juveniles con 8 individuos y 4 asignados a la categoría de crías (poppies).

A partir de la presencia de huesos penianos, se identificó un número mínimo de machos que alcanza los 19 individuos. Esta cifra debe ser considerada como mínima, ya que no se aplicó ningún otro criterio para afinar la identificación de sexo entre los restos de otáridos.

Otra característica interesante de señalar, esta dada por la baja frecuencia de mamíferos terrestres, en donde se describe la presencia de al menos un 
Tabla 1. Restos faunísticos recuperados desde Bahía Colorada (modificado de Legoupil 1997).

\begin{tabular}{c|l|c|c|c|c} 
& TAXON & NRD & \%NR & NMI & NMI\% \\
\hline \multirow{2}{*}{ Mamíferos marinos } & Otaridae & 4267 & 70,3 & 63 & 43,4 \\
\cline { 2 - 6 } & Delfinidae & 43 & 0,7 & 2 & 1,4 \\
\hline \multirow{2}{*}{ Mamíferos terrestres } & Artiodactyla & 43 & 0,7 & 2 & 1,4 \\
\cline { 2 - 6 } & Myocastor coipus & 2 & 0,0 & 1 & 0,7 \\
\hline \multirow{2}{*}{ Aves } & \multicolumn{1}{|c|}{ SUBTOTAL } & 4355 & 71,7 & 68 & 47 \\
\hline & Diomedea sp. & 6 & 0,1 & 1 & 0,7 \\
\cline { 2 - 6 } & Spheniscus magellanicus & 1679 & 27,7 & 68 & 46,9 \\
\cline { 2 - 6 } & Phalacrocorax sp. & 23 & 0,4 & 6 & 4,1 \\
\cline { 2 - 6 } & Tachyeres pteneres & 1 & 0,0 & 1 & 0,7 \\
\cline { 2 - 6 } & Milvago chimango & 1716 & 28,3 & 77 & 53,1 \\
\cline { 2 - 6 } & SUBTOTAL & 6071 & 100 & 145 & 100
\end{tabular}

huemul y un guanaco. Los restos de éstos animales corresponden a fragmentos de diáfisis de huesos largos, que muestran evidentes signos de haber sido fracturados intencionalmente para extraer la médula. La situación insular en la que se encuentra el sitio permite plantear que los escasos restos de artiodáctilos registrados corresponderían a porciones anatómicas transportadas desde otra área, pues resulta poco plausible que la isla Englefield hubiera albergado este tipo de animales.

En relación a las aves, los análisis de Lefèvre (1997) destacan la predominancia abrumadora de cormoranes, seguidos muy de lejos por quetros y pingüinos. A pesar de que el número de individuos calculado para cormorán supera levemente el de pinnípedos, resulta evidente que la subsistencia -en términos de aporte energético- se basó en la caza de lobos marinos, particularmente individuos adultos Arctocephalus australis.

Finalmente, cabe indicar que no se registraron acumulaciones importantes de moluscos ni tampoco parecen haber sido importantes los peces, registrándose un total de 855 vértebras y huesos craneales para éstos últimos.

El sitio Bahía Buena (BB), excavado por OrtizTroncoso en la década de 1970', corresponde a un basural conchífero emplazado a 12 msnm actual, inmediatamente arriba de una antigua terraza marina que tendría su origen en la transgresión marina del Holoceno medio. El área excavada alcanzó los 31 $\mathrm{m}^{2}$, entregando una notable industria sobre obsidiana verde y variados instrumentos óseos característicos de la tradición de cazadores marinos tempranos. El yacimiento cuenta con 3 dataciones ${ }^{14} \mathrm{C}$ hechas sobre carbones de los primeros niveles de ocupación, las que arrojaron las siguientes fechas: $5210 \pm 110$, $5770+110$ y $5895+65$ años AP (Ortiz-Troncoso 1975, 1977-78).

La información arqueozoológica, obtenida a partir de los trabajos de Lefèvre (1989) y San Román (2004, 2007), se resume en la tabla 2.

$\mathrm{Al}$ igual que en Bahía Colorada, Bahía Buena destaca por la alta frecuencia de los restos de pinnípedo, siendo predominante Arctocephalus australis. En relación a la estructura de edades de los pinnípedos recuperados, se observa la alta frecuencia de adultos de entre 8 a 14 años $(n=14)$, y subaldultos de entre 3 y 8 años $(n=14)$, registrándose un único ejemplar de Arctocephalus en la categoría igual o menor de 1 año (yearling). Además, se determinó un marcado predominio de machos, con una relación de aproximadamente 10:1 en relación a hembras de esta especie.

El perfil de mortalidad descrito para pinnípedos en este sitio permite corroborar que los cazadores que habitaron en Bahía Buena no explotaron una colonia de reproducción de Arctocephalus australis, siendo probable que la acumulación fuese originada por la cacería de individuos aislados.

Otra característica interesante, esta dada por la baja frecuencia de mamíferos terrestres, principalmente en el caso de Artiodáctilos, en donde se describe la presencia exclusiva de guanaco. En el caso específico de este taxón, se pudo determinar que los restos ubicados en la capa superior del sitio fueron depositados por un evento de ocupación diferente, datada en 1630+40 años AP. Esta constatación permite descontar buena parte de los restos de guanaco del conjunto originado por cazadores marinos tempranos. 
Tabla 2. Restos faunísticos recuperados desde Bahía Buena (modificado de San Román 2007).

\begin{tabular}{|c|c|c|c|c|c|}
\hline & TAXON & NRD & \%NRD & NMI & $\% \mathrm{NMI}$ \\
\hline \multirow{5}{*}{ Mamíferos marinos } & Otaridae & 4072 & 41.9 & 35 & 12,5 \\
\hline & Delphinidae & 135 & 1,39 & 4 & 1,4 \\
\hline & Lontra sp. & 2 & 0.02 & 1 & 0,4 \\
\hline & Cetacea & 13 & 0.13 & 1 & 0,4 \\
\hline & Subtotal & 4222 & 43.5 & 41 & 14,6 \\
\hline \multirow{4}{*}{ Mamíferos terrestres } & Artiodactyla & 142 & 1,47 & 3 & 1,1 \\
\hline & Canidae & 4 & 0.04 & 1 & 0,4 \\
\hline & Ctenomys sp. & 1 & 0.01 & 1 & 0,4 \\
\hline & Subtotal & 147 & 1.52 & 5 & 1,8 \\
\hline \multirow{14}{*}{$\begin{array}{c}\text { Aves (Basado en datos de } \\
\text { Lefèvre (1989) }\end{array}$} & Macronectes sp. & 1 & 0.01 & 1 & 0,4 \\
\hline & Diomedea chrysostoma & 5 & 0.05 & 2 & 0,7 \\
\hline & Procellaria cinerea & 2 & 0.02 & 1 & 0,4 \\
\hline & Aptedonytes patagonica & 1 & 0.01 & 1 & 0,4 \\
\hline & Spheniscus magellanicus & 30 & 0.3 & 3 & 1,1 \\
\hline & Phalacrocorax sp. & 4758 & 49 & 217 & 77,2 \\
\hline & Milvago chimango & 3 & 0.03 & 1 & 0,4 \\
\hline & Tachyeres pteneres & 4 & 0.04 & 1 & 0,4 \\
\hline & Anas sibilatrix & 15 & 0.15 & 5 & 1,8 \\
\hline & Anas georgica & 2 & 0.02 & 1 & 0,4 \\
\hline & Catharacta skua & 1 & 0.01 & 1 & 0,4 \\
\hline & Pterocnemia pennata & 1 & 0.01 & 1 & 0,4 \\
\hline & Subtotal & 4823 & 49.6 & 235 & 83,6 \\
\hline & TOTAL & 9192 & 100 & 281 & 100,0 \\
\hline
\end{tabular}

En relación a las aves, destaca la predominancia abrumadora de cormoranes, taxón que supera en número de restos determinados y en número de individuos a todos los taxones de vertebrados descritos para el sitio. Los demás taxones se ubican muy atrás en cuanto a cantidad de restos e individuos (pingüinos, patos, albatros). A diferencia de Bahía Colorada, en Bahía Buena se observa una mayor diversidad taxonómica de especies de aves explotadas. A pesar de que el número de individuos calculado para cormorán supera el de pinnípedos, el principal aporte para la subsistencia se basó en la caza de Arctocephalus australis.

Por último, cabe indicar que se registraron acumulaciones importantes de moluscos, aunque no existen datos cuantitativos ni cualitativos que permitan obtener una estimación acerca de su importancia en el depósito. La misma situación es observada para los peces, registrándose como única referencia la presencia de 351 restos óseos.

El yacimiento de Punta Santa Ana 1 (PSA-1), que corresponde al campamento más antiguo de cazadores marinos de Patagonia meridional, fue descubierto y excavado por Omar Ortiz-Troncoso a inicios de la década del setenta ${ }^{2}$. El sitio, ubicado en la costa sureste de península Brunswick (5337’41" Sur/ 7056'26" Oeste) se emplaza en el borde sureste de la punta Santa Ana, inmediatamente al norte de bahía San Juan (Figura 1 y 2). Corresponde a un conchal emplazado a 12 metros snm, por sobre una antigua terraza marina de la transgresión del Holoceno medio. La excavación abarcó una superficie de $29 \mathrm{~m}^{2}$ y alcanzó una potencia máxima de 55 $\mathrm{cm}$. Entre los hallazgos destacan los restos de un individuo de sexo femenino sepultado dentro de la matriz de conchal. Los análisis bioantropológicos han indicado un notable desarrollo de paleopatologías asociables a actividades que incluirían la boga, hecho que reforzaría la adscripción de este individuo a una tradición de cazadores marinos con tecnologías de navegación (Constantinescu 2001). Por otro lado, análisis isotópicos han mostrado una dieta marcadamente marina $\left(\delta^{15} \mathrm{~N}=20.2 / \delta^{13} \mathrm{C}=-13.24\right)$ (Borrero et al 2001:123).

El yacimiento posee 5 dataciones radiocarbónicas que lo sitúan como la evidencia más antigua

2 Los antecedentes del sitio estan basados en Ortiz-Troncoso (1973, 1974, 1975 , 1977-78 y 1979). 


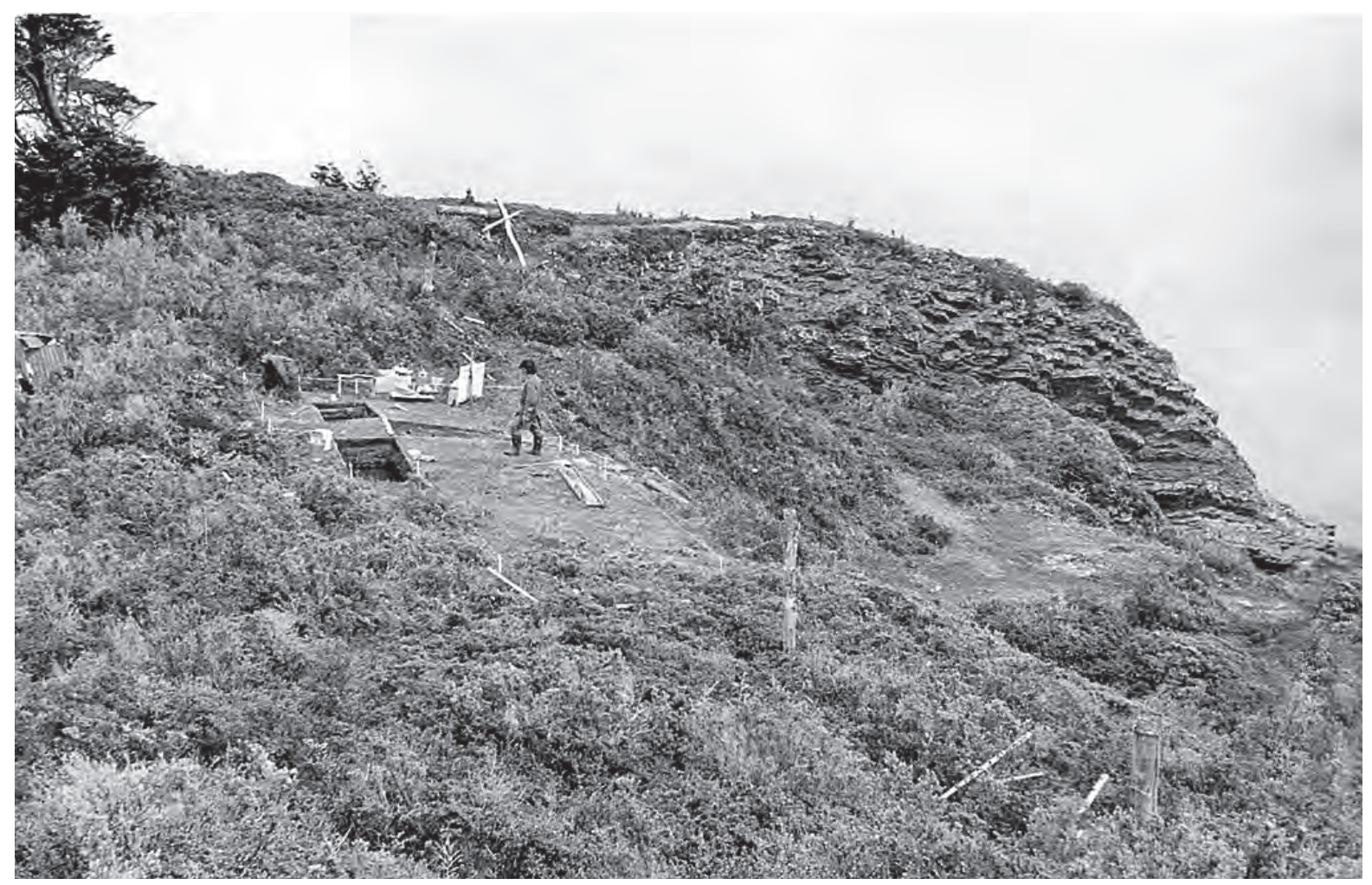

Fig. 2. Fotografía del yacimiento PSA-1 durante la excavación de 1972 (Foto de Ortiz-Troncoso, Archivo CEHA-Instituto de la Patagonia).

de cazadores marinos de Patagonia (Tabla 3). Un nuevo análisis sobre los restos humanos arrojó un resultado coherente con los obtenidos previamente, destacando que la fecha obtenida para un hueso de guanaco del nivel superior (III) permite suponer que los fechados realizados en la década de 1970 sobre conchas podrían estar rejuvenecidos ${ }^{3}$.

3 Al aplicar la corrección de 550 años de efecto reservorio local (San Roman et al 2009) sobre las fechas para conchas del nivel inferior de ocupación, se obtienen diferencias de casi un mileno con las del esqueleto humano y el guanaco del nivel superior.

\section{ANÁLISIS ARQUEOZOOLÓGICO DE PSA-1}

Materiales y Métodos

El análisis se efectuó sobre los restos de mamíferos recuperados durante la excavación efectuada por Omar Ortiz-Troncoso (1975). Hasta la fecha, sólo los restos líticos y las aves habían sido objeto de investigaciones detalladas (Schidlowsky 1999; Lefèvre 1989). En este trabajo, al igual que en los análisis previos de Lefèvre (op cit) y Schidlowsky (op. Cit), no se consideró la procedencia estratigráfica de los restos, opción metodológica basada en la

Tabla 3. Fechados radiocarbónicos para PSA-1.

\begin{tabular}{c|c|c|c|ccc|c|} 
Código & Referencia & $\begin{array}{c}\text { Nivel } \\
\text { Ocupación }\end{array}$ & material & Edad Convencional AP & ว13C (\%) \\
\hline Gif-2928 & Ortiz-Troncoso 1975 & I (inferior) & Concha & 5620 & \pm & 120 & $\mathrm{~s} / \mathrm{n} \mathrm{ref}$ \\
\hline GrN-7612 & Ortiz-Troncoso 1977-78 & I (inferior) & Concha & 6410 & \pm & 70 & $\mathrm{~s} / \mathrm{n} \mathrm{ref}$ \\
\hline Gif s/n ref & Soto-Heim 1992 & II (medio) & Huesos humanos & 6540 & \pm & 110 & $\mathrm{~s} / \mathrm{n} \mathrm{ref}$ \\
\hline Beta-252913 & Este trabajo & II (medio) & Huesos humanos & 6290 & \pm & 50 & $-11,6$ \\
\hline Beta-252914 & Este trabajo & III (superior) & Guanaco & 6330 & \pm & 50 & -21 \\
\hline
\end{tabular}


Tabla 4: Restos faunísticos recuperados desde Punta Santa Ana-1.

\begin{tabular}{|c|c|c|c|c|c|}
\hline & TAXON & NRD & $\% N R D$ & NMI & NMI $\%$ \\
\hline \multirow{4}{*}{ Mamíferos marinos } & Arctocephalus australis & 8 & 0,4 & \multirow{2}{*}{9} & \multirow{2}{*}{14,3} \\
\hline & Otaridae & 692 & 37,3 & & \\
\hline & Delfhinidae & 1 & 0,1 & 1 & 1,6 \\
\hline & Cetacea & 22 & 1,2 & 1 & 1,6 \\
\hline \multirow{7}{*}{ Mamíferos terrestres } & Lama guanicoe & 46 & 2,5 & \multirow{2}{*}{2} & \multirow{2}{*}{3,2} \\
\hline & Artiodactyla & 30 & 1,6 & & \\
\hline & Canidae & 6 & 0,3 & 1 & 1,6 \\
\hline & Myocastor coipus & 1 & 0,1 & 1 & 1,6 \\
\hline & Mammalia & 260 & 14 & & \\
\hline & Indeterminados & 177 & 9,5 & & \\
\hline & SUBTOTAL & 1243 & 67 & & \\
\hline \multirow{10}{*}{ Aves $^{4}$} & Diomedea exulans & 9 & 0,5 & 2 & 3,2 \\
\hline & Procellaria cinerea & 34 & 1,8 & 7 & 11,1 \\
\hline & Pygoscelis papua & 5 & 0,3 & 2 & 3,2 \\
\hline & Spheniscus magellanicus & 81 & 4,4 & 4 & 6,3 \\
\hline & Phalacrocorax sp. & 462 & 24,9 & 25 & 39,7 \\
\hline & Chloephaga picta & 14 & 0,8 & 4 & 6,3 \\
\hline & Chloephaga rubidiceps & 6 & 0,3 & 3 & 4,8 \\
\hline & Tachyeres pteneres & 1 & 0,1 & 1 & 1,6 \\
\hline & SUBTOTAL & 612 & 33 & \multirow[b]{2}{*}{63} & \multirow[b]{2}{*}{100} \\
\hline & TOTAL & 1855 & 100 & & \\
\hline
\end{tabular}

homogeneidad cultural del depósito arqueológico, evidenciada por la presencia de herramientas diagnósticas de la tradición cultural Englefield en todos los niveles de ocupación identificados (Ortiz-Troncoso 1975, 1979). Además, los nuevos fechados radiocarbónicos realizados sobre el sitio avalan la integridad cronológica del yacimiento (vid supra).

Las principales variables relevadas se refirieron a la identificación anatómica y taxonómica de los restos, el registro de modificaciones naturales y culturales sobre los huesos y la determinación de rangos de edad y sexo, efectuada específicamente para el caso de otáridos.

Resultados

El estudio se efectuó sobre 1243 restos óseos de mamíferos, logrando identificar taxonómicamente el 70\% del total de los materiales analizados (Tabla 4).

Los resultados de la determinación taxonómica mostraron una predominancia abrumadora de restos de otáridos, que corresponden al principal grupo de mamíferos del yacimiento. En este sentido, cabe destacar que más del $95 \%$ de los vertebrados recuperados corresponden a animales de ambiente costero y/o pelágico.
En relación a la identificación de modificaciones naturales sobre los restos, podemos indicar sumariamente el buen estado de conservación de los restos óseos, con una baja incidencia de meteorización (sensu Beherensmeyer 1978), como también de acción de raíces (1\%) y de daños generados por la acción de dientes de animales.

a) Otáridos

Se registró la predominancia de Arctocephalus australis (Zimmermann 1783) a partir de 7 mandíbulas en donde se detectó un marcado desarrollo de la fosa macetérica (Legoupil 198990). Además, se agrega un canino maxilar con presencia de anillos de crecimiento exteriores, rasgo propio del género Arctocephalus. El único caso asignable a Otaria flavescens (Shaw 1800) corresponde a un fémur de talla considerable, sin fusión de epífisis, que correspondería a un macho juvenil de esta especie.

A partir del cálculo del número mínimo de individuos (NMI) se determinó la presencia de al menos 9 especímenes a partir de primera falange del dígito 1 anterior derecho (Tabla 5).

$4 \quad$ Basado en datos de Lefèvre (1989). 
Tabla 5. Los restos de Otaridos de Punta Santa Ana 1.

\begin{tabular}{|c|c|c|c|c|c|}
\hline Unidad Anatómica & NRD & MNE & NMI & MAU & $\% \mathrm{MAU}$ \\
\hline Cráneo & 35 & 6 & 6 & 6 & 100,0 \\
\hline Dientes aislados & 3 & - & - & - & - \\
\hline Hemi-Mandíbula & 9 & 4 & 4 & 2 & 33,3 \\
\hline Hioides & 10 & 10 & 3 & 1,4 & 23,3 \\
\hline Cervicales & 12 & 11 & 3 & 1,6 & 26,7 \\
\hline Torácicas & 31 & 20 & 3 & 1,3 & 21,7 \\
\hline Lumbares & 20 & 15 & 3 & 2,5 & 41,7 \\
\hline Sacrum & 3 & 3 & 1 & 3 & 50,0 \\
\hline Caudales & 21 & 21 & 3 & 2,6 & 43,3 \\
\hline $\begin{array}{l}\text { Vértebra } \\
\text { indeterminada }\end{array}$ & 16 & - & - & - & - \\
\hline Costillas & 155 & 38 & 3 & 1,3 & 21,7 \\
\hline Esternebras & 19 & 13 & 3 & 1,6 & 26,7 \\
\hline Escápula & 30 & 7 & 5 & 3,5 & 58,3 \\
\hline Humero & 7 & 3 & 2 & 1,5 & 25,0 \\
\hline Radio & 15 & 9 & 7 & 4,5 & 75,0 \\
\hline Ulna & 11 & 7 & 4 & 3,5 & 58,3 \\
\hline Escafolunar & 5 & 5 & 3 & 2,5 & 41,7 \\
\hline Ulnar & 4 & 4 & 4 & 2 & 33,3 \\
\hline Carpo I & 5 & 5 & 4 & 2,5 & 41,7 \\
\hline Carpo II & 3 & 3 & 2 & 1,5 & 25,0 \\
\hline Carpo III & 2 & 2 & 2 & 1 & 16,7 \\
\hline Carpo IV & 4 & 4 & 3 & 2 & 33,3 \\
\hline Accesorium & 1 & 1 & 1 & 0,5 & 8,3 \\
\hline Metacarpo I & 9 & 7 & 4 & 3,5 & 58,3 \\
\hline Metacarpo II & 6 & 6 & 4 & 3 & 50,0 \\
\hline Metacarpo III & 8 & 8 & 4 & 4 & 66,7 \\
\hline Metacarpo IV & 9 & 9 & 6 & 4,5 & 75,0 \\
\hline Metacarpo V & 11 & 11 & 6 & 5,5 & 91,7 \\
\hline Coxal (Hemi-pélvis) & 18 & 11 & 6 & 5,5 & 91,7 \\
\hline Fémur & 8 & 6 & 5 & 3 & 50,0 \\
\hline Tibia & 12 & 7 & 4 & 3,5 & 58,3 \\
\hline Fíbula & 2 & 1 & 1 & 0,5 & 8,3 \\
\hline Patella & 3 & 3 & 2 & 1,5 & 25,0 \\
\hline Talus & 4 & 3 & 3 & 1,5 & 25,0 \\
\hline Calcáneo & 3 & 3 & 2 & 1,5 & 25,0 \\
\hline Cuboides & 7 & 7 & 5 & 3,5 & 58,3 \\
\hline Navicular & 5 & 5 & 3 & 2,5 & 41,7 \\
\hline Tarso I & 4 & 4 & 3 & 2 & 33,3 \\
\hline Tarso II & - & - & - & - & - \\
\hline Tarso III & 1 & 1 & 1 & 0,5 & 8,3 \\
\hline Metatarso I & 10 & 6 & 4 & 3 & 50,0 \\
\hline Metatarso II & 10 & 10 & 5 & 5 & 83,3 \\
\hline Metatarso III & 7 & 7 & 5 & 3,5 & 58,3 \\
\hline Metatarso IV & 8 & 8 & 5 & 4 & 66,7 \\
\hline Metatarso V & 6 & 5 & 4 & 2,5 & 41,7 \\
\hline Metapodio & 2 & - & - & - & - \\
\hline Falanges & 123 & 90 & 9 & 1,7 & 28,3 \\
\hline Baculum & 3 & 2 & 2 & 2 & 33,3 \\
\hline
\end{tabular}

7009
Para la identificación de sexo se utilizaron como criterios la presencia de huesos penianos, medidas de ancho rostral, ancho máximo para la corona de caninos (Schiavini 1990) y la utilización de medidas de elementos del póstcraneo (San Román 2010). La combinación de criterios permitió determinar de manera preliminar una proporción entre machos y hembras de 2:1 ( $n=4: 2$ ). Las categorías de edad incluyen 1 poppie o yearling 5,4 individuos juveniles y 4 especimenes adultos. Esta información permite descartar que los cazadores de PSA-1 estuvieran explotando una colonia de reproducción. Entonces, resulta probable que los lobos marinos consumidos en el campamento hayan sido capturados en diferentes sucesos de caza, que pudieron incluir tanto la captura en el mar, como en apostaderos en tierra. El reducido número de individuos depositados en el yacimiento sugiere un tiempo muy corto de ocupación total para la formación del depósito.

La determinación de frecuencias de representación de las distintas porciones esqueletales de otáridos permiten registrar una importante representación del cráneo y del esqueleto apendicular, destacando una notable baja frecuencia de elementos del esqueleto axial, principalmente de costillas y vértebras torácicas (Fig. 3)

Basados en la información sobre densitometría ósea para otáridos de Sudamérica, publicada por Borella et al (2007), se evaluó si la representación diferencial de elementos en este conjunto podía

5 Aun no contamos con criterios osteométricos que nos permitan afinar la determinación de edad para cachorros de Arctocephalus sp.

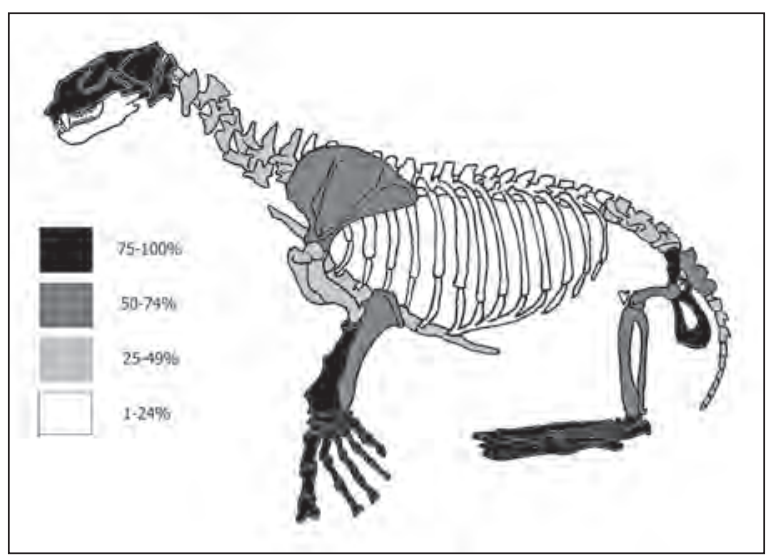

Fig. 3. Representación de elementos anatómicos de otáridos en PSA-1 (\%MAU). 


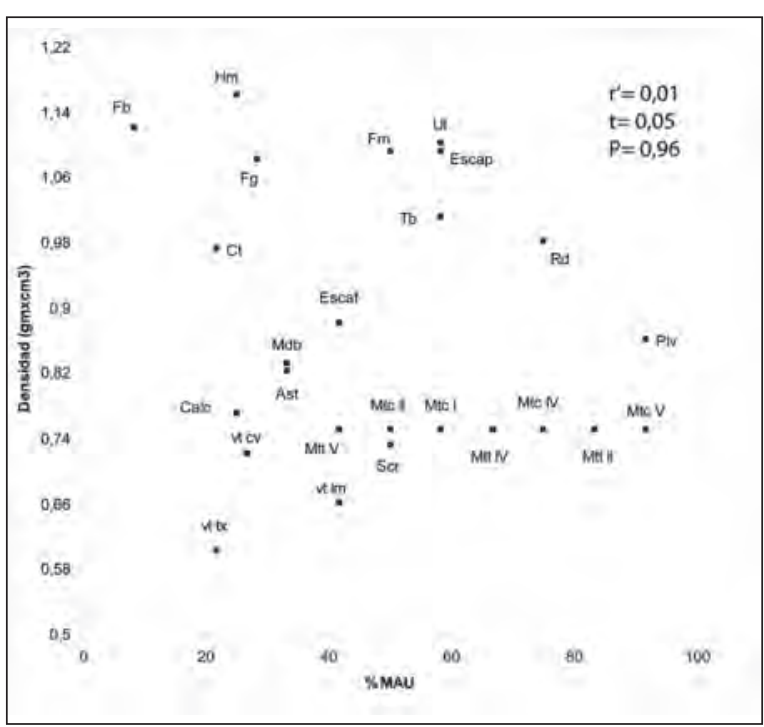

Fig. 4. Gráfico de dispersión de densidad ósea y \%MAU para otáridos de PSA-1.

explicarse por decaimiento diferencial asociado a la densidad mineral ósea. Los resultados arrojaron un grado de correlación no significativo ( $r^{\prime}=0,01 ; \mathrm{P}$ $\leq 0,96$ ), permitiendo descartar esta explicación (Fig. 4).

También, evaluamos si la distribución de las diferentes partes del esqueleto de pinnípedos podía refrendar conductas asociadas a transporte diferencial de carcasas, mediatizada por criterios de utilidad económica. Para ello se utilizó información referida al índice de utilidad económica obtenido para Otaria flavescens (San Román 2009). Los resultados no mostraron correlación significativa entre ambas variables ( $\left.r^{\prime}=-0,299 ; P=0,297\right)$, aunque muestran un grado mayor de correlación que los valores densitométricos (Fig. 5).

El registro de marcas de origen antrópico mostró una frecuencia de 13,9\% para las huellas de corte sobre los restos $(\mathrm{n}=98)$. A partir de la distribución de las marcas, hemos interpretado evidencias de cuereado, refrendada por marcas en diáfisis medial de tibia $(n=1)$ y radio $(n=1)$, como también en la porción mesodistal de mandíbula ( $n=1)$, aunque en una muy baja frecuencia. Luego, se observan marcas asignables al desmembramiento, tales como las ubicadas en el borde de la cavidad glenoidea $(n=4)$, bajo la cabeza del fémur $(n=4)$, en los cóndilos occipitales $(n=1)$ y en epífisis proximal y distal de ulna. En relación a marcas en falanges, metapodios, carpianos y tarsales, estas corresponderían también a marcas asociadas al desmembramiento-trozamiento de las

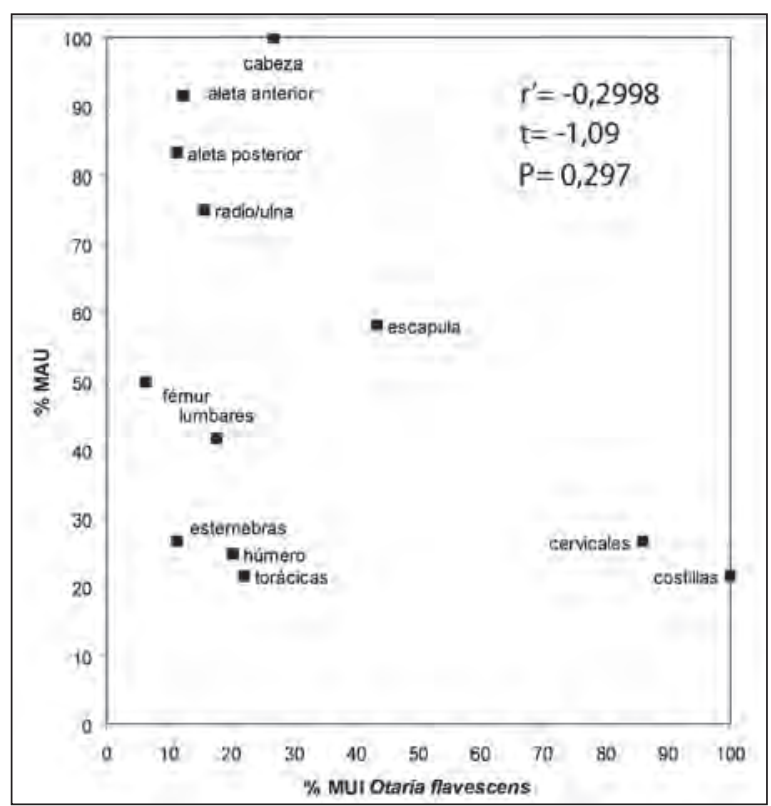

Fig. 5. Gráfico de dispersión de \% MUI y \%MAU para otáridos de PSA-1.

aletas. Además, se detectaron marcas en vértebras torácicas y lumbares asociadas a la extracción de carne de estos elementos, refrendadas por marcas paralelas o subparalelas en uno o ambos lados de los procesos espinosos. Para las vértebras se observaron marcas ubicadas en las facetas articulares, en la porción ventral, asociables a desmembramiento de secciones de la espina. También se observaron otras menos frecuentes en las facetas articulares de costillas, probablemente asociadas al desmembramiento de éstas.

En relación a la presencia de huesos con alteraciones térmicas que podrían asignarse a acción culinaria (cocción), identificamos 13 casos. La evidencia corresponde a marcas leves y/o muy acotadas a pequeñas superficies de los huesos, generalmente en facetas articulares $y / o$ articulaciones que presentan cambios de coloración producto de golpes de fuego. Muchas de estas marcas pueden ser explicadas por la acción de calor y/o llamas sobre superficies óseas desprovistas de tejido blando. Los restos identificados corresponden a:

-Costillas: proximal con pequeñas tinciones de color negro en sus epífisis $(n=4)$.

-Cráneo: occipital, con manchas de color negro acotadas a ambos cóndilos. En otro caso se observó tinción negra en la faceta articular de cóndilo mandibular $(n=2)$. 
-Escápula: tinción de color negro acotada a cavidad glenoidea $(\mathrm{n}=1)$. distal ( $n=1)$.

-Radio: coloración negra acotada en epífisis

-Ulna: borde de olécranon con mancha acotada de color negro $(\mathrm{n}=1)$.

-Fémur: pequeña tinción de color negro en epífisis proximal $(\mathrm{n}=1)$.

-Metacarpo: en borde de epífisis proximal se observa una mancha de color café $(\mathrm{n}=1)$.

-Metatarso: punto de color negro en epífisis proximal $(\mathrm{n}=2)$.

Si bien, se ha registrado una bajísima incidencia de trazas de cocción en elementos anatómicos de lobo marino, se comprueba la existencia de dichas prácticas en este yacimiento. Probablemente la baja frecuencia pueda explicarse por la dificultad en la generación de alteraciones, asociadas al tiempo de exposición de los huesos y la cobertura de tejido blando que intermedia entre éstos y la fuente de calor. Por otro lado, existe la posibilidad que en mucho de los casos en los que los huesos de otáridos se presentan quemados ( $n=250$, equivalente al 35,7\% del total de huesos de lobo) se haya obliterado la presencia de estos indicadores, generalmente poco extensos y muy acotados a ciertas porciones de los huesos, preferentemente en facetas articulares y/o epífisis.

Finalmente, la baja incidencia de este tipo de alteraciones no permite contrastar la existencia de patrones sistemáticos de cocción de porciones anatómicas, aunque la distribución de las marcas están recurrentemente emplazadas en los extremos articulares y/o epífisis. En este sentido, parecería coherente postular que el cráneo, la escápula y el radio + ulna pudieron ser sometidos a cocción como unidades. En el caso del fémur, en donde no se evidencia alteración en distal, podría eventualmente interpretarse su cocción junto a la tibia (articulados). Para el caso de metacarpos y metatarsos, la ausencia de huellas de exposición al calor en distal podría sugerir la preparación de aletas enteras (falanges articuladas a metapodios). La confirmación de la existencia de estas unidades de preparación, requerirán incluir información de otros sitios de cazadores marinos tempranos que permitan dar sustento a ésta propuesta.

\section{b) Artiodactyla}

El orden Artiodactyla, que en esta región incluye a huemul (Hippocamelus bisulcus [Molina, 1782]) y guanaco (Lama guanicoe [Müller, 1776]), está representado por un total de 76 restos. A partir de la revisión de elementos óseos en los que es posible discriminar entre ambos taxones, pudimos confirmar la presencia exclusiva de restos de Lama guanicoe.

Los materiales recuperados del yacimiento representan al menos a 3 guanacos (Tabla 6), e incluyen un juvenil menor a 30 meses a partir de una epífisis proximal de tibia sin fusionar, y al menos dos adultos a partir de dos diáfisis proximales de tibia del mismo lado con sus epífisis fusionadas (Puig y Monge 1983). Debemos señalar que no fue posible determinar sexo entre los materiales de la colección (Tabla 6).

A partir del cálculo de frecuencias para las distintas porciones anatómicas, se observa la predominancia de elementos del esqueleto apendicular posterior, seguido por elementos del miembro anterior, que incluye escápula. Luego se registran cervicales y una costilla (Figura 6 y Tabla 6). Para tratar de discernir las posibles causas de dicha distribución diferencial de elementos anatómicos, procedimos en primer lugar a evaluar si se podía explicar dicha representación por decaimiento diferencial de unidades relacionada con diferencias en la densidad mineral ósea de éstas.

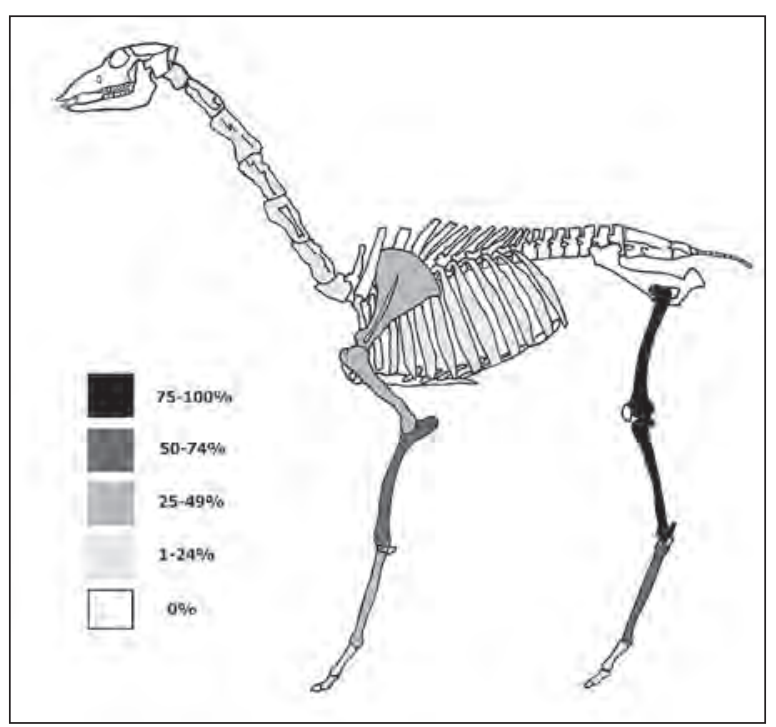

Fig. 6. Representación de elementos óseos de Artiodactyla. 
Tabla 6: Los restos de Lama guanicoe de PSA-1

\begin{tabular}{|c|c|c|c|c|c|c|}
\hline Unidad Anatómica & & NRD & MNE & NMI & MAU & \%MAU \\
\hline Cervicales & & 2 & 2 & 1 & 0,29 & 19,3 \\
\hline Costillas & & 3 & 1 & 1 & 0,08 & 5,3 \\
\hline Escápula & & 1 & 1 & 1 & 0,5 & 33,3 \\
\hline Húmero & $\mathrm{ms}$ & 1 & 1 & 1 & 0,5 & 33,3 \\
\hline \multirow{3}{*}{ Radioulna } & $\mathrm{px}$ & 1 & \multirow{3}{*}{2} & \multirow{3}{*}{1} & \multirow{3}{*}{1} & \multirow{3}{*}{66,7} \\
\hline & $\mathrm{ms}$ & 1 & & & & \\
\hline & ds & 2 & & & & \\
\hline Carpo II & & 1 & 1 & 1 & 0,5 & 33,3 \\
\hline Carpo III & & 1 & 1 & 1 & 0,5 & 33,3 \\
\hline Metacarpo & & 1 & 1 & 1 & 0,5 & 33,3 \\
\hline \multirow{2}{*}{ Fémur } & $\mathrm{ms}$ & 7 & \multirow{2}{*}{3} & \multirow{2}{*}{2} & \multirow{2}{*}{1,5} & \multirow{2}{*}{100} \\
\hline & ds & 3 & & & & \\
\hline \multirow{3}{*}{ Tibia } & $\mathrm{px}$ & 3 & \multirow{3}{*}{3} & \multirow{3}{*}{3} & \multirow{3}{*}{1,5} & \multirow{3}{*}{100} \\
\hline & $\mathrm{ms}$ & 6 & & & & \\
\hline & ds & 2 & & & & \\
\hline \multicolumn{2}{|l|}{ Calcáneo } & 4 & 3 & 2 & 1,5 & 100 \\
\hline \multicolumn{2}{|l|}{ Metatarso } & 2 & 2 & 1 & 1 & 66,7 \\
\hline \multicolumn{2}{|l|}{ Metapodio } & 4 & 2 & 1 & 1 & 66,7 \\
\hline \multicolumn{2}{|l|}{ Falanges } & 5 & 3 & 1 & 0,125 & 8,3 \\
\hline \multicolumn{2}{|l|}{ Diáfisis Hueso largo } & 26 & - & - & - & - \\
\hline TOTAL & & 76 & & & & \\
\hline
\end{tabular}

Para ello, utilizamos los valores densitométricos publicados por Stahl (1999:1352), que incluyen una corrección a partir del ajuste de forma ("shape adjusted"), que genera valores de densidad mucho más certeros que los publicados previamente (Elkin y Zanchetta 1991).

Los resultados no mostraron correlación entre ambas variables ( $\left.\mathrm{r}^{\prime}=0.014 ; \mathrm{P}=0.968\right)$, pudiendo desechar esta explicación para la representación de huesos de guanaco en el sitio. Luego, procedimos a evaluar si existía algún tipo de correlación entre la representación de partes esqueletarias y el índice de utilidad carnea publicado para guanaco (Borrero 1990). Los resultados no muestran correlación significativa ( $\left.\mathrm{r}^{\prime}=0,155 ; \mathrm{P}=0.325\right)$, pero se observa una correspondencia mayor que para valores densitométricos (Fig. 8).

Si bien, no se comprobó estadísticamente la correlación entre valores de rinde económico y la representación de partes del esqueleto de guanacos, se puede plantear que la distribución observada puede ser explicada por el ingreso de elementos anatómicos y/o porciones puntuales al yacimiento. En el caso específico de fémur y tibia, se pude plantear que éstos habrían ingresado como unidad de trozamiento (Fig.6 y 8).
Una característica del conjunto de restos de guanaco es la gran frecuencia de modificaciones que evidencian conductas culturales asociadas al procesamiento de los animales, en donde destacan las fracturas $(n=45)$ que implicarían el aprovechamiento de médula ósea. Del conjunto de restos que

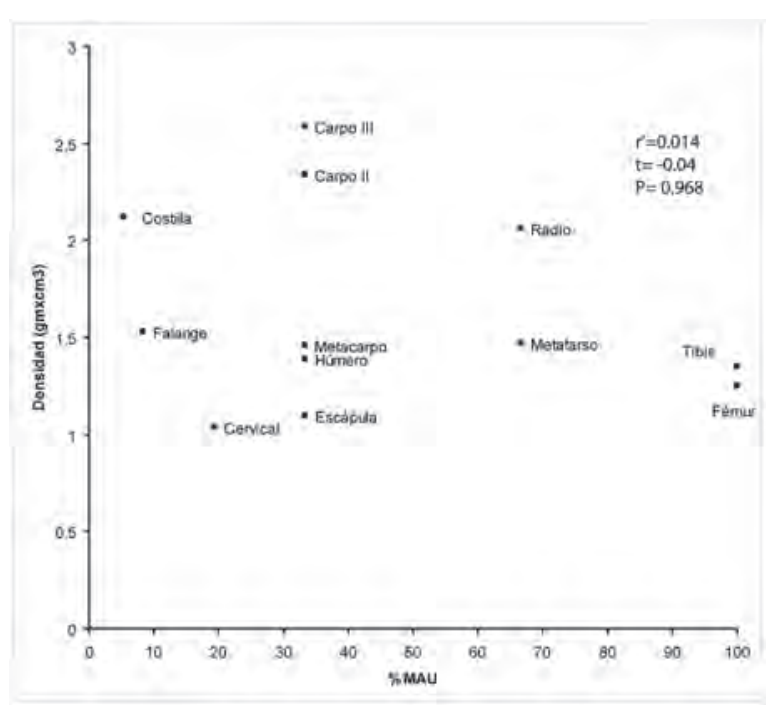

Fig. 7. Gráfico de dispersión de densidad mineral ósea y \%MAU. 


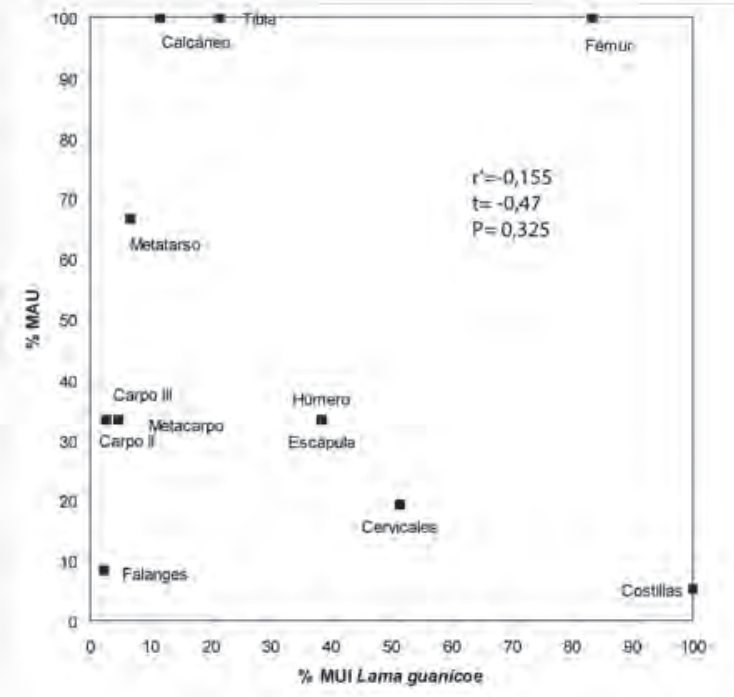

Fig. 8. Gráfico de dispersión de \% MUI y \%MAU para guanacos.

evidencian fracturas en estado fresco, se ha podido determinar que 25 casos presentan uno o mas rasgos asociados a fractura por percusión, tales como negativos de lascados, charnelas, puntos de impacto, lascas, entre otros. En general, podemos indicar que las fracturas se evidencian principalmente sobre los huesos del esqueleto apendicular, puntualmente sobre fémur y tibia, reforzando la idea del aprovechamiento intensivo de la médula de este ungulado.

La subsistencia a partir del cálculo de aporte energético de taxones relevantes.

En relación a la información arqueozoológica descrita, se comprueba la importancia de los pinnípedos en el total del conjunto faunístico. En relación al número de restos determinados, los lobos marinos superan en frecuencia a todos los taxones descritos. Para el caso del NMI, son los cormoranes los que lideran el recuento con 25 individuos, seguidos por otáridos con 9 especimenes. A pesar de ello, al aplicar un criterio de conversión entre especimenes de diversas especies por su equivalencia en aporte energético (kilocalorías), obtenemos cifras que exacerban aun más el primer lugar en el ranking de importancia de los pinnípedos en la subsistencia de los ocupantes del sitio. Utilizando un valor de referencia de 70400 kilocalorías para un Arctocephalus macho adulto (Orquera y Piana
1993-94), obtenemos un total de 633600 kilocalorías para los 9 especimenes de PSA-1. El aporte de 25 especimenes de cormorán solo alcanzarían 37525 kilocalorías (basados en Schiavini 1993:211). Esto equivale a que por cada lobo marino se requieren 47 cormoranes para igualar el aporte energético. En esta lógica, fuera del primer lugar obtenido por los lobos marinos, debemos destacar que la mayoría de la fauna explotada es de ámbito marino. En cuanto a los mamíferos terrestres registrados, se ha calculado la presencia de al menos un guanaco juvenil y dos guanacos adultos. El aporte energético de éstos al conjunto es notablemente inferior al de pinnípedos, pero logran posicionarse en el segundo lugar de importancia. El valor de referencia utilizado para guanaco es de 71506 kilocalorías para un juvenil y 85741 kilocalorías para uno adulto (basado en Schiavini 1993:210). Sin embargo, debemos utilizar con cautela las conversiones, ya que los cálculos de número mínimo de individuos pueden obviar el hecho de que algunos especimenes están representados por sólo algunos escasos elementos anatómicos. Esta observación es válida tanto para pinnípedos como para camélidos en el conjunto de PSA-1.

\section{DISCUSIÓN}

Un elemento surgido luego del análisis tiene relación con las distribuciones diferenciales de elementos anatómicos de pinnípedo en PSA-1. Como describiéramos, la representación diferencial de elementos no se explica por destrucción diferencial mediada por densidad mineral ósea ( $\left.r^{\prime}=0,01, P=0,96\right)$. Tampoco se obtuvo una correlación significativa entre los valores de \%MAU y los índices de utilidad carnea (\%MUI) [r'=0,299; $\mathrm{P}=0.297]$. Sin embargo, la representación gráfica de la dispersión de valores de \%MAU y \%MUI tiende a describir una curva de utilidad reversa (sensu Binford 1978). Las implicaciones de esta distribución resultan coherentes con la notable sub-representación de la caja torácica (costillas y vértebras torácicas). Esta información permite plantear que estos elementos pudieron ser transportados fuera del yacimiento, quizás como parte de las provisiones llevadas hacia otros sitios, durante los cambios de residencia. Para evaluar la plausibilidad de esta hipótesis, ensayamos una comparación con las evidencias de los sitios de Bahía Buena y Bahía Colorada. 


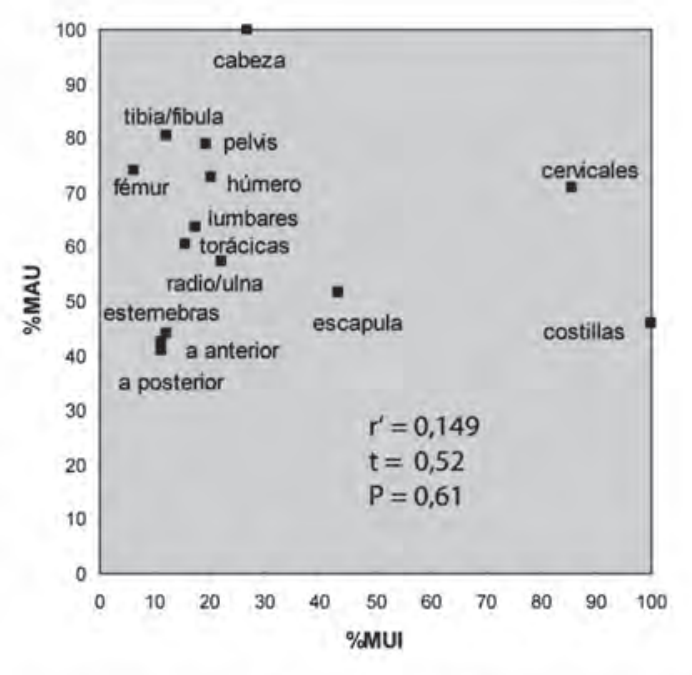

Bahía Buena

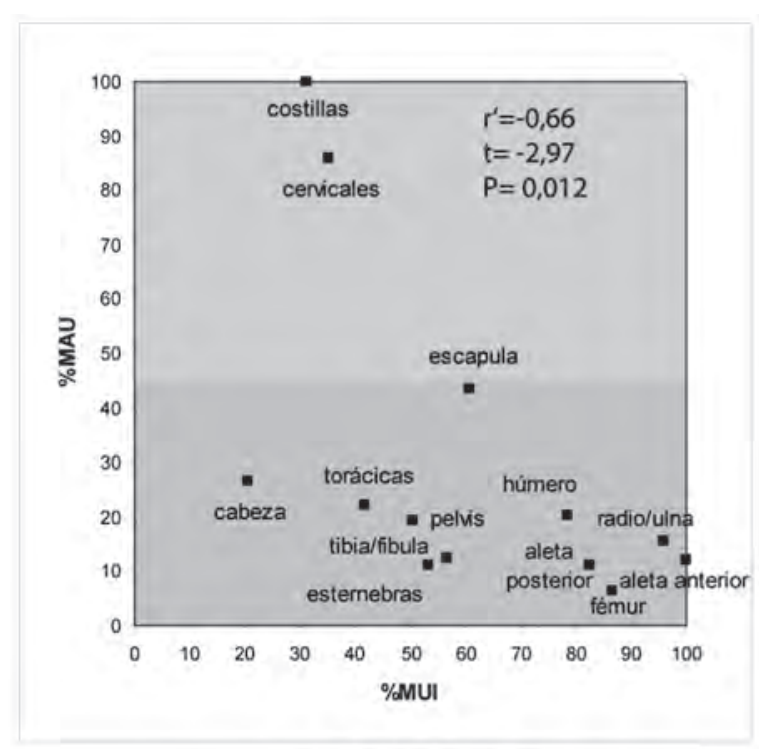

Bahía Colorada

Fig. 9. Gráficos de dispersión de \%MAU y \%MUI de otáridos para los sitios Bahía Buena y Bahía Colorada.

Para el caso de Bahía Buena, no se observó correlación entre \%MAU y \%MUI [r'=0,149; $\mathrm{P}=0,612)$, destacando el bajísimo valor de interdependencia entre ambas variables. En cambio, para Bahía Colorada se pudo describir una correlación altamente significativa entre ambas variables $\left[\mathrm{r}^{\prime}=-0,66 ; \mathrm{P}=0,01\right]$ (Fig. 9).

Al observar el gráfico de dispersión de valores de Bahía Colorada, encontramos un patrón similar al observado en Punta Santa Ana, en donde se describe una curva reversa de utilidad económica. Esta información permite sugerir que tanto en Punta Santa Ana como en Bahía Colorada, los patrones de consumo y descarte de lobos marinos fueron semejantes, caracterizados por la utilización de porciones de bajo rinde económico. Este hecho permite suponer que las porciones económicamente más relevantes fueron transportadas y/o consumidas en otras locaciones, probablemente en otros campamentos residenciales.

En relación a esta última idea, es importante observar otras de las propiedades descritas para los yacimientos de cazadores marinos tempranos. A partir de información reportada por Schidlowsky (1999), calculamos tasas de depositación para artefactos líticos por unidades de área para $\mathrm{BC}, \mathrm{BB}$ y PSA-1. Los valores obtenidos son muy parecidos entre Bahía Colorada y Bahía Buena [49,6 y 43,3 restos $/ \mathrm{m}^{2}$, respectivamente]. Para Punta Santa Ana 1 los valores observados son extremadamente bajos $\left(4,2\right.$ restos $\left./ \mathrm{m}^{2}\right)$.

Luego, al efectuar el mismo tipo de cálculo considerando los restos de fauna (mamíferos y aves), obtuvimos los valores siguientes: Bahía Colorada $=$ 62.5 restos $/ \mathrm{m}^{2}$; b) Bahía Buena $=295,5$ restos $/ \mathrm{m}^{2}$; Punta Santa Ana $=63,9$ restos $\mathrm{x} \mathrm{m}^{2}$.

Ahora bien, para darle sentido a estos datos, podemos plantear que las tasas de depositación para restos de fauna se relacionarían con la importancia de las diferentes locaciones, en términos de la intensidad y/o frecuencia de utilización por parte de poblaciones de cazadores-recolectores. Es decir, Bahía Colorada y Punta Santa Ana pueden ser interpretados como campamentos de uso esporádico, con intensidad de uso mucho menor que para el caso de Bahía Buena. En relación a las tasas referidas a material lítico, debemos señalar que pueden estar condicionadas a la distancia entre los diferentes sitios y la ubicación de la fuente de obsidiana verde, que estaría en algún lugar próximo al mar de Otway (Morello et al 2001). Este hecho explicaría porque Bahía Colorada alcanza tasas de depositación semejantes a Bahía Buena, dado que en Bahía Colorada no se habría practicado estrategias de curaduría de obsidiana, al ser un recurso ubicado 
dentro del rango de apropiación desde el sitio. Por otro lado, las tasas de descarte observadas en Punta Santa Ana expresarían conductas de curaduría de material lítico muy exacerbadas.

Al agregar la información relativa a la distribución de elementos anatómicos de pinnípedos y rinde económico, encontramos que en Bahía Colorada y en Punta Santa Ana se describen curvas reversas de utilidad, mientras que en Bahía Buena se observa una bajísima correlación para estas variables. Esta línea de evidencia refuerza la idea de sitios residenciales que pueden integrar una red de sitios de jerarquía diferenciada, la que podría asociarse, entre otros factores, a las características locales de emplazamiento, condiciones de reparo, riqueza local de recursos, entre otras. En particular, resulta plausible que el sitio de Punta Santa Ana haya correspondido a un lugar de tránsito entre locaciones residenciales de mayor importancia, como en el caso de Bahía Buena y otro nodo, aun no registrado en las costas del estrecho de Magallanes. En este sentido, Legoupil observó a partir de los trabajos que realizó en isla Englefield, que el sitio de Bahía Colorada pudo corresponder a un campamento satélite o secundario en relación al sitio de Englefield 1. Ello, a partir de la notable diferencia de tamaños, riqueza y diversidad de restos de industria lítica y recursos faunísticos acumulados en uno y otro yacimiento (Legoupil 1997:207).

En relación a la movilidad de estos grupos, resulta interesante discutir algunas ideas a partir de la evidencia aportada por los restos de guanaco. La información sobre restos de guanaco registrados en PSA-1, particularmente en lo referido a la representación de partes del esqueleto, permite sugerir que se ingresaron porciones anatómicas puntuales, tales como el miembro posterior (fémur + tibia) y no animales enteros al yacimiento. En este sentido, al considerar que las inmediaciones de Punta Santa Ana se habrían caracterizado por un ambiente boscoso, resulta esperable la predominancia de huemul como taxón terrestre económicamente relevante $e^{7}$. Además, a la luz de la información paleoambiental disponi-

7 Sarmiento de Gamboa, español que dirigió una de las expediciones de reconocimiento del estrecho de Magallanes durante el siglo XVI, señala: "Llegamos á la punta de Santana, y subimos á una mesa alta donde hay grandes rasos y cabañas de muy buena hierba para ganado, y vimos dos venados grandes y muy gordos: y un arcabucero mató el uno, y el que huyó tenía grandes astas" (2000:141). ble para el Holoceno medio (McCulloch y Davies 2001), se describen condiciones de temperatura y humedad mayores a las descritas hoy en día en la región, hecho que potencialmente habría propiciado un desarrollo mucho más importante del bosque, pudiendo haber alcanzado una expansión territorial que pudo alejar aun más los actuales límites con la estepa, y por ende, con los territorios ocupados por guanacos. Esta evidencia refuerza la idea de que los guanacos no habrían estado disponibles localmente, por lo que la hipótesis de transporte de partes de animales a PSA-1 desde otra zona resulta plausible. Entonces, podemos plantear que los habitantes de PSA-1 incluyeron dentro de sus desplazamientos zonas ecotonales de bosque y estepa, en donde habrían podido capturar guanacos. Dichas zonas se habrían ubicado al menos a una cincuentena de kilómetros al norte de PSA-1. Al comparar con la información registrada en Bahía Colorada, encontramos tendencias muy parecidas, reflejadas por la presencia de elementos del esqueleto apendicular, que nunca son muy abundantes y que permiten confirmar que durante los cambios de residencia, se transportan sistemáticamente provisiones de alimento, en este caso, porciones de guanaco.

\section{CONCLUSIONES Y EXPECTATIVAS}

El análisis efectuado sobre PSA-1 ha permitido verificar el rol central ocupado por los otáridos en la subsistencia de los ocupantes del yacimiento, hecho ya constatado para los demás sitios de cazadores marinos tempranos de Patagonia meridional (Legoupil 1997, San Román 2007). Por otro lado, al aplicar otras líneas de análisis sobre la evidencia arqueofaunística, describimos que los campamentos adscritos a la tradición cultural Englefield no solo presentan diferencias en cuanto a intensidad de uso, a partir de tasas de descarte de restos de fauna, sino que ésta también se asocia al consumo y descarte diferencial de elementos anatómicos de lobo marino. Entonces, podríamos plantear que los sitios de PSA-1 y BC corresponderían a locaciones de uso esporádico o de tránsito entre nodos más importantes, como el caso de Bahía Buena y probablemente Englefield 1. Evaluar esta hipótesis requerirá, entre otras cosas, poder estimar el tiempo de formación de los depósitos para poder ajustar las tasas de depositación en función de esta variable crítica. 
A partir de las reconstrucciones de perfiles de mortalidad (sexo y edad) de pinnípedos para los tres sitios de cazadores marinos tempranos ubicados en mar de Otway y estrecho de Magallanes (Bahía Colorada, Bahía Buena y Punta Santa Ana 1) se puede descartar la presencia de sitios de reproducción de pinnípedos dentro de los respectivos rangos de acción desde cada uno de estos campamentos. Esta constatación resulta coherente con el mapa actual de distribución de colonias de reproducción de lobos marinos, particularmente con la de Arctocephalus australis, ubicadas en el borde Pacífico del archipiélago Fuego-.Patagónico (Sielfeld et al. 1978).

En relación a este punto, debemos señalar que se ha planteado un alto grado de especialización en la explotación de otáridos para estos grupos de cazadores (Legoupil 1997). Una tarea relevante será evaluar en que grado ésta especialización pudo regular las estrategias de movilidad, ya que sería esperable la instalación de campamentos estivales asociados con la explotación de colonias de reproducción, probablemente emplazadas hacia el litoral Pacífico. Para avanzar sobre esta cuestión, resultará fundamental determinar estacionalidad en el uso de los diferentes yacimientos, pues si este principio se cumple, las zonas del estrecho de Magallanes y del mar de Otway deberían haber sido ocupadas durante el otoño $e$ invierno, para luego ser abandonadas durante la primavera y el verano. En este sentido, podemos señalar que existiría sustento para dicha modalidad de uso estacional, a partir del registro de aves que están disponibles exclusivamente durante el invierno austral (Phalacrocorax bransfildensis) y que han sido identificadas en el sitio de Englefield y también en Bahía Buena.

Para finalizar, cabe consignar que deberemos ajustar las escalas de trabajo que utilizamos en relación a estas nuevas problemáticas. Esto implica ampliar geográficamente el alcance de nuestras investigaciones sobre cazadores marinos tempranos, en especial a zonas que tradicionalmente nunca fueron incorporadas a los esfuerzos de búsqueda, como por ejemplo el litoral Pacífico. La ampliación de la escala geográfica y la incorporación de nuevas técnicas que permitan lecturas arqueológicas cada vez más detalladas (estacionalidad), permitirán contribuciones sustanciales en la generación de conocimiento sobre los grupos de cazadores-recolectores marinos que colonizaron el confín meridional del planeta.

\section{BIBLIOGRAFÍA}

BEHERENSMEYER, A. K. 1978. Taphonomic and Economic Information from Bone Weathering. Paleobiology (4):150-162.

BINFORD, L. R. 1978. Nunamiut Ethnoarchaeology. Academic Press, New York.

BORELlA, F., M. A. GUTIERREZ, H. R. FODERE y J. F. MERLO. 2007. Estudio de densidad mineral ósea para dos especies de otáridos frecuentes en el registro arqueofaunístico patagónico (Otaria flavescens y Arctocephalus australis). En Desenterrando Huesos, recolectando piedras, develando arcanos...VI Jornadas de Arqueología de Patagonia, Editado por F. Morello, A. Prieto, M. Martinic y G. Bahamonde. CEQUA, Punta Arenas.

BORRERO, L. 1990. Fuego-Patagonian bone assemblages and the problem of communal guanaco hunting. In Hunters of the recent past, Editado por L. B. Davis y B. O. K. Reeves, pp. 373-399. Unwin Hyman, London.

CONSTANTINESCU, F. 2001. Canal Maule y Punta Santa Ana: el habitus cazador recolector marítimo femenino. (Patrones óseos característicos del modo de vida canoero en el extremo sur de Chile). Anales del Instituto de la Patagonia Serie Ciencias Humanas 29:163-182.

ELKIN, D. y O.R. ZANCHETTA. 1991. Densitometría ósea de camélidos - Aplicaciones arqueológicas. Actas del X Congreso de Arqueología Argentina 3: 195-204.

EMPERAIRE, J. y A. LAMING. 1961. Les Gisements des Iles Englefield et Vivian dans la Mer d'Otway. Journal de la Société des Américanistes 50:7-75.

FIORE, D. 2002. Diseños y técnicas en la decoración de artefactos: el caso de los sitios del canal Beagle, Tierra del Fuego. Actas del XIII Congreso Nacional de Arqueología Argentina.

LEFÈVRE, C. 1989. L'Avifaune de Patagonie Austral et ses relations avec L'Homme au cours des six derniers millenaires. These de Doctorat, Paris I - Panthéon-Sorbonne.

LEGOUPIL, D. 1989-90. La Identificación de los Mamíferos Marinos en los Sitios Canoeros de Patagonia: Problemas y Constataciones. Anales del Instituto de la Patagonia, Serie Cs. Humanas 19:101-115.

-1997. Bahía Colorada (Ile Englefield). Les premiers chasseurs de mammifères marins de Patagonie australe. Recherche sur les Civilisations, Paris.

MCCULLOCH, R. D. y S. DAVIES. 2001. Late-glacial and Holocene palaeoenvironmental change in the central Strait of Magellan, southern Patagonia. Palaeogeography, Palaeoclimatology, Palaeoecology 173:143-173. 
MORELlO, F., M. SAN ROMÁN, A. PRIETO Y C. STERN. 2001. Nuevos antecedentes para una discusión arqueológica en torno a la obsidiana verde en Patagonia Meridional. Anales del Instituto de la Patagonia, Serie Cs. Humanas, 29: 129-148.

OCAMPO, C. 1994. Proyecto "Conservación períodica, camino Punta Arenas-San Juan, 72B090, Km 30 al Km 54 (sectorial). Camino acceso a Fuerte Bulnes, Km. 0.0 al 4.7 y camino acceso a bahía Mansa, Km. 0.0 al 1.5 (ISAR). Estudio de impacto a los Bienes Culturales.

ORQUERA, L.A. y E.L. PIANA. 1993-94. Lancha Packewaia: Actualización y rectificaciones. Relaciones de la Sociedad Argentina de Antropología XIX: 325-375.

ORTIZ-TRONCOSO, O. 1973. Aspectos Arqueológicos de la Península de Brunswick. Anales del Instituto de la Patagonia 6:109-130.

-1974. L'Occupation préhistorique d'une ancienne ligne de rivage dans le Détroit de Magellan. Doctorat, Ecole Pratique des Hautes Etudes.

-1975. Los Yacimientos de Punta Santa Ana y Bahía Buena (Patagonia Austral). Excavaciones y Fechados Radiocarbónicos. Anales del Instituto de la Patagonia 7:93-122.

-1977-78. Nuevas dataciones radiocarbónicas para Chile Austral (Patagonia y Tierra del Fuego). Boletín del Museo Arqueológico de La Serena 16:244-250.

-1979. Punta Santa Ana et Bahía Buena: deux gisements sur une ancienne ligne de rivage dans le détroit de Magellan. Journal de la Société des Américanistes 60 (6):133-204.

PUIG, S. y S. MONGE. 1983. Determinación de la edad en Lama guanicoe (Muller). Deserta 7:246-270.

SAN ROMÁN, M., F. MORELLO y A. PRIETO. 2002. Nuevos antecedentes sobre explotación de recursos faunísticos en el mar de Otway y canales adyacente. Anales del Instituto de la Patagonia, Serie Cs. Humanas 30:147-154.

SAN ROMÁN, M. 2004. L'exploitation des mammifères chez les chasseurs maritimes du site de Bahía Buena: économie des anciens canoeros de Patagonie (Détroit de Magellan). DEA Préhistoire-Ethnologie-Antropologie, Université Paris I Pantheon-Sorbonne.

-2005. Nuevos hallazgos de sitios de cazadores recolectores marinos tempranos en isla Englefield, mar de Otway. Magallania 33(2):173-176.
-2007. La explotación de mamíferos en el sitio de Bahía Buena: economía de canoeros tempranos de Patagonia (estrecho de Magallanes, Chile). En Arqueología de Fuego-Patagonia. Levantando piedras, desenterrando huesos... y develando arcanos...VI Jornadas de Arqueología de Patagonia, Editado por F. Morello, A. Prieto, M. Martinic and G. Bahamonde, pp. 295-310. CEQUA, Punta Arenas.

-2009. Anatomia económica de Otaria flavescens [Shaw 1800]. En Zooarqueología y Tafonomía en el confín del Mundo. Monografías Arqueológicas $N^{\circ} 1$, Editado por P. López, I. Cartajena, C. García y F.Mena, pp. 169-179. Universidad Internacional SEK, Santiago.

-2010 (MS). La explotación de recursos faunísticos. en el sitio Punta Santa Ana 1: Estrategias de subsistencia de grupos de cazadores marinos tempranos de Patagonia Meridional. Tesis de grado en arqueología; Universidad de Chile, Santiago.

SAN ROMÁN, M, K. SALAS y M. FONTUGNE. 2009. Primeros avances en la reconstrucción de secuencias de ocupación de cazadores recolectores marinos en el estrecho de Magallanes, Patagonia meridional. En Arqueología de Patagonia: una mirada desde el último confín, Editado por F. S. M. Salemme, M. Alvarez, E. Piana, M. Vázquez y E. Mansur, pp. s/n ref. Utopías Ushuaia.

SCHIAVINI, A. 1990. Estudio de la relación entre el hombre y los pinnípedos en el proceso adaptativo humano al canal Beagle, Tierra del Fuego, Argentina. Tesis Doctoral, Universidad de Buenos Aires.

SCHIDLOWSKY, V. 1999. Comportements techno-économiques et identité culturelle des premiers chasseurs maritimes et des chasseurs terrestres de Patagonie Australe. Tesis de Doctorado, Paris-I Panthéon-Sorbonne.

SIELFELD, W., C. VENEGAS, A. ATALAH y J. TORRES. 1978. Prospección de otáridos en las costas de Magallanes. Anales del Instituto de la Patagonia 9:157-170.

SOTO-HEIM, P. 1992. Le peuplement Paléo-Indien et archaique d'Amérique du sud. Étude anthropologique et analyse comparative avec le peuplement sub-actuel. Museum National d'Histoire Naturelle (A L'Institut de Paléontologie Humaine). These de Doctorat.

STAHL, P. 1999. Structural density of domesticated south american camelid skeletal elements and the archaeological investigation of prehistoric Andean Ch'arki. Journal of Archaeological Science 26:1347-1368. 